\title{
Cell-based therapy for idiopathic pulmonary fibrosis
}

\author{
Qi Lu ${ }^{1,2}$, Ahmed H. K. El-Hashash ${ }^{1,2}$ \\ ${ }^{1}$ The University of Edinburgh-Zhejiang International campus (UoE-ZJU Institute), Haining, China; ${ }^{2}$ Centre of Stem Cell and Regenerative \\ Medicine Schools of Medicine \& Basic Medicine, Hangzhou, China \\ Contributions: (I) Conception and design: All authors; (II) Administrative support: Ajda Yang; (III) Provision of study materials or patients: None; \\ (IV) Collection and assembly of data: All authors; (V) Data analysis and interpretation: All authors; (VI) Manuscript writing: All authors; (VII) Final \\ approval of manuscript: All authors. \\ Correspondence to: Ahmed H. K. El-Hashash, PhD. Associate Professor, The University of Edinburgh-Zhejiang International Campus, (UoE-ZJU), \\ ZJE Building, Haining 314400, China. Email: hashash05@yahoo.co.uk.
}

\begin{abstract}
Idiopathic pulmonary fibrosis (IPF) is an example of interstitial lung diseases that is characterized by chronic, progressive, and fibrotic lung injuries. During lung fibrosis, normal healthy lung tissues are replaced by remarkably destroyed alveolar architecture and altered extracellular cell matrix. These changes eventually cause severe disruption of the tightly-controlled gas exchange process and reduction of lung compliance that ultimately lead to both respiratory failure and death. In the last decade, progress has been made toward understanding the pathogenesis of pulmonary fibrosis, and two novel disease-modifying therapies were approved. However, finding more effective treatments for pulmonary fibrosis is still a challenge, with its incidence continues to increase globally, which is associated with significantly high mortality, morbidity and economical healthcare burden. Different stem cell types have recently emerged as a promising therapy for human diseases, including lung fibrosis, with numerous studies on the identification, characterization, proliferation and differentiation of stem cells. A large body of both basic and pre-clinical research on stem cells has been recently translated to patient care worldwide. Herein, we review recent advances in our understanding of the pathophysiology of IPF, and types of cells used in IPF cell-based therapies, including alveolar and mixed lung epithelial cells, different stem cell types (MSCs, ADSCs, IPSCs...etc.), endogenous lung tissue-specific stem cells, and circulating endothelial progenitors (EPCs). We also discuss recent studies on the applications of these cells in IPF therapy and their delivery routes, effective doses for cell therapy, and timing of delivery. Finally, we discuss attractive recent and current clinical trials conducted on cell-based therapy for IPF.
\end{abstract}

Keywords: Lung; fibrosis; stem cell; cell therapy; idiopathic pulmonary fibrosis (IPF)

Received: 13 April 2019; Accepted: 18 June 2019; Published: 16 August 2019.

doi: $10.21037 /$ sci.2019.06.09

View this article at: http://dx.doi.org/10.21037/sci.2019.06.09

\section{Introduction}

Pulmonary fibrosis is common in different inflammatory lung diseases, such as interstitial pneumonia, chronic obstructive pulmonary disease (COPD), and silicosis. The lungs have a very limited ability to regenerate, compared to other organs (1), and there is currently no effective clinical drug treatment for pulmonary fibrosis.

Idiopathic pulmonary fibrosis (IPF) is a life-threatening lung disease whose pathogenesis is associated with steady- state imbalance in pulmonary epithelial cells $(2,3)$. Currently, there is no effective treatment for this endstage lung fibrosis disease. However, some FDA-approved therapeutic agents, including pirfenidone and nintedanib, can clearly reduce the average decrease in the function of the lung in the IPF patients $(3,4)$.

Current studies have investigated whether the pathogenesis of IPF is related to chronic epithelial injury that leads to abnormalities of the wound healing process, and both fibroblast proliferation and activation, rather than 
inflammation $(2,3,5)$. The abnormal healing of wounds can cause a loss of the balance between the extracellular matrix formation and degradation $(6,7)$. The IPF causes involve multiple mechanisms and factors, but the exact reason is still unknown. For example, smoking, environmental/ occupational contaminants, microbial agents, chronic aspiration of gastroesophageal reflux and genetic abnormalities, are key factors that are associated with IPF (8). In addition, both the genetic predisposition and genome mutations are linked to the IPF pathology. Thus, mutations in the SFTPC gene, which codes for surfactant protein C (SP-C), the adenosine triphosphate binding cassette A3 gene, surfactant protein A2 (SP-A2) gene, telomerase gene or other genes, which play roles in host defense, adhesions between cells or repairing DNA, can contribute to the lung fibrosis $(9,10)$. Other factors and enzymes are also important for the development of IPF. The telomerase activity, for instance, varies in different cell types and affects lung stem cells $(11,12)$, while increased IPF telomerase activity in lung fibroblasts make these cells have certain anti-apoptotic functions (12).

IPF is still an unexplained chronic and progressive pulmonary fibrosis disease, with a poor prognosis. IPF patients have an average survival time of 3 to 5 years $(13,14)$. The main reason for the failure of traditional therapies is due to a lack of proper understanding of the IPF pathogenesis. Both managing and treating the medical conditions associated with IPF comorbidities, including the COPD, gastro-esophageal reflux, obstructive sleep apnea and inhibiting the pathways which trigger the fibrogenic process, are the emphasis of the conventional therapeutic approaches (15).

The American Thoracic Society (ATS) has updated the IPF Clinical Practice Guide to include some changes in 2011 (16). These changes include an objection against the IPF therapy with prednisone combined with both $\mathrm{N}$-acetylcysteine and azathioprine, which were found to increase the death rate by almost ten times. They also involve an opposition against the use of warfarin, imatinib, and ambrisentan as well as sildenafil, macitentan and bosentan in the treatment of IPF patients (16). Meanwhile, the new ATS guideline has continued previous recommendation for $\mathrm{N}$-acetylcysteine (conditional recommendation against monotherapy for IPF) and antacid therapy in patients without symptoms of gastro-esophageal reflux (conditional recommendation) $(2,3,16)$.

Lung transplantation is currently a feasible scheme and successful curative therapy for some IPF patients with limited comorbidity symptoms (7). However, the lack of donor organs and limited patient suitability for transplantation make lung transplantation less applicable and, therefore, other therapeutic approaches have been investigated and tested in last decades $(2,3,5,17,18)$. Recent discoveries of IPF mechanisms have helped in designing new treatment regimens. For example, new potential IPF targets include angiotensin receptor inhibitors, which hinder the proliferation of fibrotic fibroblasts induced by ANG II (19), NOX-4 antagonists (NADPH oxidase 4) that downregulate the reduction of $\mathrm{O}_{2}$ to reactive oxygen species (ROS) (20), and galectin-3 inhibitors that block TGF- $\beta$ induced $\beta$-catenin activation and attenuate lung injury (21). These targets also involve FoxO3, which is an important integrator of pro-fibrotic signaling pathways in fibrotic lungs and, therefore, reconstitution of FoxO3 pharmacology is currently a novel therapeutic approach (22). In addition, the IPF-associated endothelial microparticles are other targets required for the fibrinolytic activitymediated fibroblast invasion in fibrotic lungs (23).

More targets and therapeutic agents are under intensive investigation and/or development, including the FDAapproved pirfenidone and nintedineb, which can treat IPF by decreasing the decline of IPF lung functions and disease progression $(4,16,24)$. Other effects of pirfenidone include preventing the deposition of hydroxyproline, procollagen I and III, inflammatory cells and transforming growth factor $\beta$ (TGF- $\beta$ ) in different lung tissues (24). Similarly, nintedanib, which is a CDK4 kinase inhibitor that acts against three tyrosine kinase receptors; PDGFR $\alpha$, VEGFR and FGFR1, can inhibit the progression of IPF by slowing down the declining rate of the forced vital capacity (FVC) in the lung (25). However, the ultimate cure for IPF remains to be seen, and other targets are still being sought.

\section{Types of cells used in the cell-based therapies of IPF}

The cell-based strategies are extensively investigated to find treatments for IPF (26-30). Cell therapy for IPF is mainly achieved by replacing damaged cells with regenerated cells and/or the administered cell paracrine properties. In this section, we will discuss recent developments in the regenerative medicine field and its applications in the cellbased therapy of IPF. In addition, recent clinical trials in for IPF will be reviewed.

A variety of cells are used in the IPF treatment studies, including lung epithelial cells type II (31), lung mixed lung 
epithelial cells (32), and different stem cell types, including lung stem cells, induced pluripotent stem cells (iPSCs), embryonic stem cells (ESCs), mesenchymal stem cells (MSCs), and adipose stem cells (ADSCs) (33-36). Notably, both endogenous alveolar epithelial and bone marrowderived mesenchymal cells are most widely investigated for the IPF treatment (37). These different cell types will be discussed in the following subsections.

\section{Alveolar epithelial cells (AECs)}

In the alveolar epithelium of the peripheral lung, alveolar epithelial type I (AECI) cells enable gas exchange with lung blood capillaries, while alveolar epithelial type II (AECII) cells secrete pulmonary surfactants that reduce alveolar surface pressure $(15,38,39)$. AECII cells can selfreplicate and serve as adult stem cells that differentiate into AECI cells during normal homeostatic turnover and when the AECI cell number is reduced by injury (40). AECII cells are, therefore, the "caretaker" cells of the alveolar compartment, since they can protect the epithelium, initiate repair processes and maintain alveolar structure, if an injury occurs. A study showed that lung fibrogenesis was reversed after transplanting AECII cells in the rodent model of bleomycin-induced (BLM) lung fibrosis (31).

AECII cells used for transplantation could be isolated from the healthy lung (31) or produced in culture from differentiated adult stem cells (17). The use of freshly isolated AECII cells is more effective and safer since they do not have tumor forming potentials, while adult stem cells may undergo abnormalities in their chromosomes, leading to the formation of malignant tumors after transplantation in the lung (41). AECII cells-derived from human embryonic or bone marrow stem cells (BMSCs) could be also transplanted into a BLM induced IPF model $(35,42)$. In addition, AECs can be produced from ESCs in culture. For example, the airway specific cells, including ciliated, Clara, basal and intermediate epithelial cells, can be formed when murine ECSs grow as embryonic bodies on surfaces coated with collagen. The culture medium of these cells is supplemented with specific growth factors before re-plating on an air liquid-interface culture $(43,44)$. Despite their sources, transplantation of AECII cells into the lungs of BLM-induced IPF animal models can lead to a remarkable reduction of collagen contents, supporting the potential function of AECII cells in healing lung injuries (33). Remarkably, recent infusions of allogeneic adult lung spheroid cells (LSCs) into fibrosis animal models can inhibit the inflammation progression and fibrosis manifestation, suggesting intrinsic adult LSCs for lung therapy (45). A summary of key preclinical and clinical studies exploring the applications of AECII, LSCs and ESCs in IPF therapy is shown in Tables 1,2.

\section{Mixed lung epithelial cells}

Since the isolation of AEC cells from the lung or generation from differentiated stem cells is a complicated process, it was proposed that the use of mixed lung epithelial cells is easier, faster and efficient for the lung cell-based therapy than AEC alone (32). The lung epithelial cell mixture expresses surfactant protein $\mathrm{C}$ in culture and in vivo. The intra-tracheal delivery of lung epithelial cell mixture into a BLM-induced animal model of fibrosis was shown to improve lung fibrosis (32).

\section{Stem cells}

Stem cells have been studied for many years as a potential treatment for the chronic diseases. Stem cells, including ESCs, ADSCs, MSCs, bone marrow stem cell (BMSCs) and endogenous lung stem/progenitor cells, have two essential properties; a controlled and unlimited self-renewal capacity, and a differentiation ability into different specific cell lines. Adult stem cells from the bone marrow, umbilical cord, and adipose tissue are commonly used for the study and potential treatment of the chronic lung diseases such as IPF $(37,49)$. Remarkably, stem cell-based tissue engineering aims to mimic the native stem cell niche and maintain stem cell function within the graft by providing appropriate microenvironmental cues in a controlled and reproducible fashion that will facilitate the application of stem cell therapy in human diseases, including IPF (50).

\section{Mesenchymal stromal/stem cells}

Adult mesenchymal stromal/stem cells (MSCs) are originally isolated from adult bone marrow stroma and exist in other tissues, such as the umbilical cord, amniotic fluid, epidermis and cord blood (51). MSCs are multipotent and, therefore, can differentiate into a wide range of cell lines $(51,52)$. MSCs tend to target damaged tissues when systemically administrated via intravenous (IV) or intraperitoneal (IP) injection $(53,54)$. Thus, intraperitoneally (IP) injected amniotic fluid stem cells, including MSCs, can migrate and be detected in different body organs such as the lung (55).

MSCs have potent anti-proliferative, anti-apoptotic, 
Table 1 Summary of key IPF preclinical study results using AECII, LSCs, ASCs \& ESCs cells

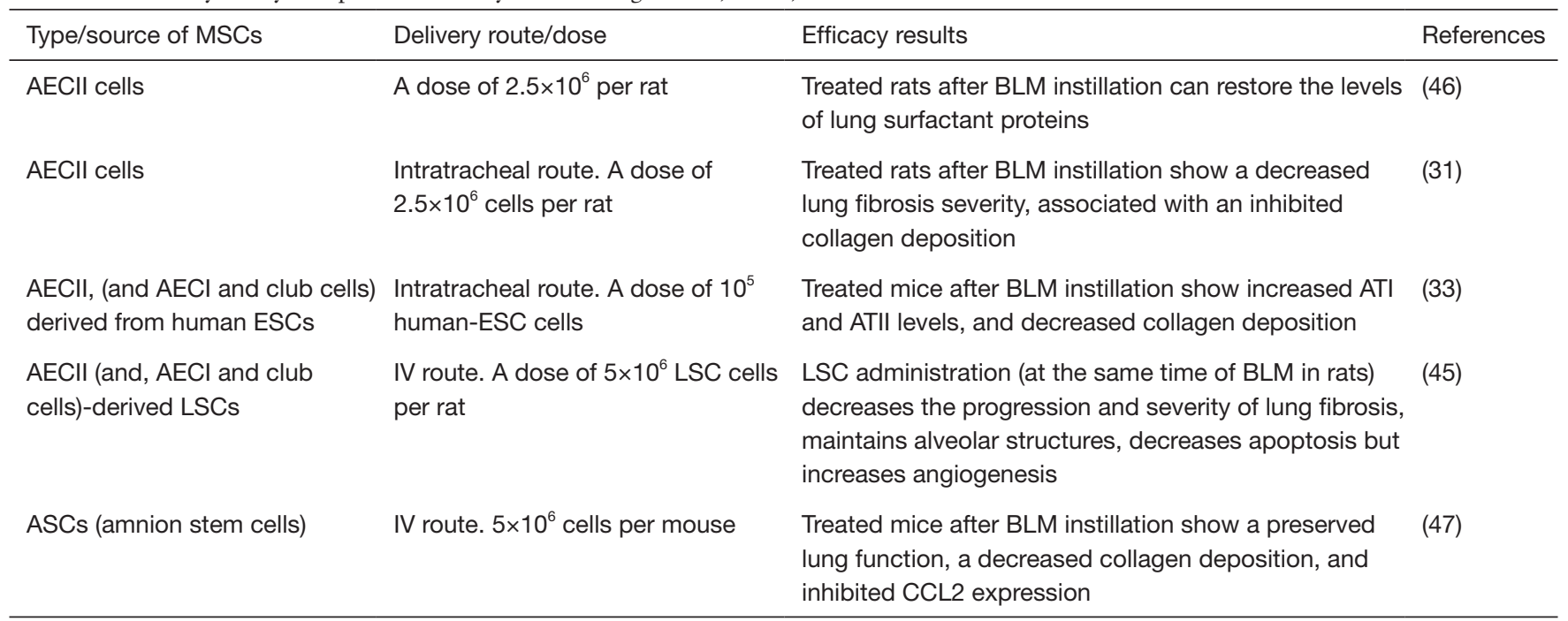

ADSCs, adipose-derived MSCs; ADSCs-SVF, autologous adipose derived stromal cells-stromal vascular fraction; AECII, alveolar epithelial type II cells; AECI, alveolar epithelial type I cells; ASCs, amnion stem cells; BLM, bleomycin; BM-hMSCs, human bone marrow-derived mesenchymal stem cells; EMT, epithelial- mesenchymal transition; IPF, Idiopathic pulmonary fibrosis; LSCs, lung spheroid cells; PDMSCs, placenta-derived mesenchymal stem cells; IV, intravenous; IP, intraperitoneal; PAH, pulmonary arterial hypertension.

Table 2 Summary of key IPF clinical human study results using AECII cells

\begin{tabular}{llll}
\hline Type/source of ADSCs & Delivery route/dose & Efficacy results & Safety results \\
\hline AECll cells & Intratracheal route. A dose of 1,000 & A halt of IPF diseases & Administrated AECII cells are (48) \\
(heterologous) & to $1,200 \times 10^{6}$ cells per patient & progression in treated patients & both safe and well tolerated \\
\hline
\end{tabular}

IPF, Idiopathic pulmonary fibrosis; AECII, alveolar epithelial type II cells; ADSCs, adipose-derived MSCs.

immune-modulatory and anti-inflammatory properties, besides their multilineage capacity, which make them have a great therapeutic potential for different diseases $(37,51,52)$. In addition, MSCs can modify the micro-environmental factors at the engraftment site that can enhance their therapeutic potential (37). Interestingly, the better understanding of the effect of extracellular environment on MSC paracrine activity, together with recent progress in bioengineering, can enhance the success of the clinical application of MSC therapy (56). Indeed, MSC therapy is a good candidate for different autoimmune diseases because of their immunomodulatory and anti-inflammatory competence $(57,58)$. A summary of key preclinical and clinical studies exploring the applications of MSCs (from different sources) in IPF therapy is shown in Tables 3-6.

\section{MSCs derived from the bone marrow (BM-MSCs)}

The bone marrow is the major source of MSCs, and BM-
MSCs have been intensively investigated in IPF treatment $(34,81)$. Remarkably, the granulocyte colony-stimulating factor (G-CSF)-augmented BM-MSCs can result in an improvement of lung healing in the animal model of lung injury (82). Similarly, BM-MSC infusion can reverse the BLM-induced lung fibrosis (69). Therefore, BM-MSCs play a key role in the healing of different lung injuries and, consequently, can alleviate the fibrosis symptoms (83). However, IPF patient-isolated BM-MSCs were recently shown to be senescent with alterations in mitochondrial functions and DNA damages (84). A summary of key preclinical/clinical studies on IPF therapy using BM-MSCs is shown in Tables 3,4.

\section{MSCs derived from the umbilical cord and placenta}

MScs derived from the aborted fetuses, umbilical cord, or discarded test-tube human embryos have high stem cell plasticity/phenotype, with low immunogenicity in 
Table 3 Summary of key IPF preclinical study results using MSCs cells

\begin{tabular}{|c|c|c|c|}
\hline Type/source of MSCs & Delivery route/dose & Efficacy results & References \\
\hline Human placental MSCs & $\begin{array}{l}\text { IV route. A dose of } 1 \times 10^{5} \text { cells per } \\
\text { mouse }\end{array}$ & $\begin{array}{l}\text { Activation of MyD88 and TGF- } \beta \text { signalling decreased } \\
\text { collagen deposition, pro-fibrotic cytokines production }\end{array}$ & (59) \\
\hline Human umbilical-MSCs & $\begin{array}{l}\text { IV route. A dose of } 1 \times 10^{6} \text { cells per } \\
\text { mouse }\end{array}$ & $\begin{array}{l}\text { Treated mice show reduced fibrosis and inflammation, } \\
\text { and decreased TIMP expression and lung cytokine } \\
\text { production, and increased MMP expression }\end{array}$ & $(61)$ \\
\hline Lung resident-MSCs & $\begin{array}{l}\text { IV route. A dose of } 0.15 \times 10^{6} \text { or } \\
0.25 \times 10^{6} \text { cells per mouse }\end{array}$ & $\begin{array}{l}\text { Treated animals have a decreased infiltration of } \\
\text { lymphocyte and granulocyte, and display a reduced } \\
\text { pulmonary damage and mitigation of the PAH } \\
\text { development }\end{array}$ & $(62)$ \\
\hline $\begin{array}{l}\text { Human BM-MSCs } \\
\text { (overexpressing microRNAs } \\
\text { let- } 7 d \text { or miR-154) }\end{array}$ & $\begin{array}{l}\text { IV route. A dose of } 5 \times 10^{4} \text { cells per } \\
\text { mouse }\end{array}$ & $\begin{array}{l}\text { B-MSCs (overexpressing let-7d) administration leads to a } \\
\text { decrease in both collagen deposition and CD45-positive } \\
\text { cells, and a shift in animal weight loss as well as }\end{array}$ & $(64)$ \\
\hline $\begin{array}{l}\text { BM-MSCs (transfected with } \\
\text { HGF) }\end{array}$ & $\begin{array}{l}\text { Intratracheal. A dose of } 3 \times 10^{6} \text { cells } \\
\text { per rat }\end{array}$ & $\begin{array}{l}\text { Treated rats show downregulated collagen deposition } \\
\text { and decreased fibrosis in Ashcroft score }\end{array}$ & $(65)$ \\
\hline BM-MSCs & $\begin{array}{l}\text { IV route. A dose of } 5 \times 10^{6} \text { cells per } \\
\text { mouse }\end{array}$ & $\begin{array}{l}\text { Treated mice after BLM instillation show decreased } \\
\text { collagen deposition and inflammation }\end{array}$ & $(66)$ \\
\hline BM-MSCs & $\begin{array}{l}\text { IV route. A dose of } 5 \times 10^{5} \text { cells per } \\
\text { mouse }\end{array}$ & $\begin{array}{l}\text { Protection of treated lung tissue after BLM instillation, } \\
\text { with inhibiting the pro-inflammatory cytokines IL-1 and } \\
\text { TNF- } \alpha\end{array}$ & $(67)$ \\
\hline BM-MSCs & IV route. A dose of $10^{6}$ cells per rat & $\begin{array}{l}\text { Treated rats after BLM instillation show a decrease of } \\
\text { pulmonary inflammation and some fibrosis factors (e.g., } \\
\text { TGF- } \beta, \text { IL-1 } \beta \text {, VEGF, TNF- } \alpha \text {, IL-6, and NOS) }\end{array}$ & $(70)$ \\
\hline BM-MSCs (human) & IV route. A dose of $5 \times 10^{5}$ per mouse & $\begin{array}{l}\text { Treated mice after BLM instillation have a reduced } \\
\text { endoplasmic reticulum stress and oxidative stress, and } \\
\text { downregulated TGF- } \beta 1 \text { production by alveolar cells }\end{array}$ & (71) \\
\hline BM-MSCs (human) & IV route. A dose of $5 \times 10^{6}$ per mouse & $\begin{array}{l}\text { Low levels of BM-MSCs engraft in BLM-induced fibrosis } \\
\text { in immunodeficient NOD/SCID and NOD/SCID/ } \beta 2 \\
\text { microglobulin }(\beta 2 M) \text { null mice }\end{array}$ & $(72)$ \\
\hline $\begin{array}{l}\text { Hypoxia-preconditioned } \\
\text { BM-MSCs }\end{array}$ & $\begin{array}{l}\text { Intratracheal route. A dose of } 5 \times 10^{5} \\
\text { cells per mouse }\end{array}$ & $\begin{array}{l}\text { Treated mice after BLM instillation show decreased } \\
\text { fibrosis and inflammation and improvement of lung } \\
\text { function }\end{array}$ & (73) \\
\hline knockdown BM-MSCs & $\begin{array}{l}\text { IV route. A dose of } 5 \times 10^{4} \text { cells } / g \\
\text { body weight }\end{array}$ & $\begin{array}{l}\text { Treated mice after BLM instillation show low levels of } \\
\text { interleukin- } 1 \mathrm{~b} \text { and apoptosis, decreased fibrosis, and } \\
\text { upregulated HGF levels }\end{array}$ & $(74)$ \\
\hline
\end{tabular}

IPF, Idiopathic pulmonary fibrosis; MSCs, mesenchymal stem cells; BM, human bone; PAH, pulmonary arterial hypertension. 
Table 4 Summary of key IPF clinical human study results using MSC cells

\begin{tabular}{|c|c|c|c|c|}
\hline Type/source of MSCs & Delivery route/dose & Efficacy results & Safety results & References \\
\hline BM-MSCs (allogenic) & $\begin{array}{l}\text { IV route. A dose of } 20 \times 10^{6}(n=3) \\
100 \times 10^{6}(n=3) \& 200 \times 10^{6} \text { cells } \\
(n=3) . \text { One dose }\end{array}$ & $\begin{array}{l}\text { Exploratory results with: } 5.4 \% \text { mean } \\
\text { decline in \% predicted DLCO and } \\
3.0 \% \text { mean decline in } \% \text { predicted } \\
\text { FVC in treated patients }\end{array}$ & $\begin{array}{l}\text { No serious adverse } \\
\text { events, but IPF } \\
\text { progression has } 2 \text { non- } \\
\text { treatment related deaths }\end{array}$ & (76) \\
\hline
\end{tabular}

IPF, Idiopathic pulmonary fibrosis; MSCs, mesenchymal stem cells; BM, human bone.

Table 5 Summary of key IPF preclinical study results using ADSCs

\begin{tabular}{|c|c|c|c|}
\hline Type/source of ADSCs & Delivery route/dose & Efficacy results & References \\
\hline ADSCs & $\begin{array}{l}\text { IV route. A dose of } 2.5 \times 10^{4} \text { or } 2.5 \times 10^{5} \\
\text { cells per mouse }\end{array}$ & $\begin{array}{l}\text { Treated mice show a decreased lung fibrosis and } \\
\text { inflammation in a dose-dependent manner }\end{array}$ & $(77)$ \\
\hline
\end{tabular}

IPF, Idiopathic pulmonary fibrosis; ADSCs, adipose-derived MSCs.

Table 6 Summary of key IPF clinical human study results using ADSCs

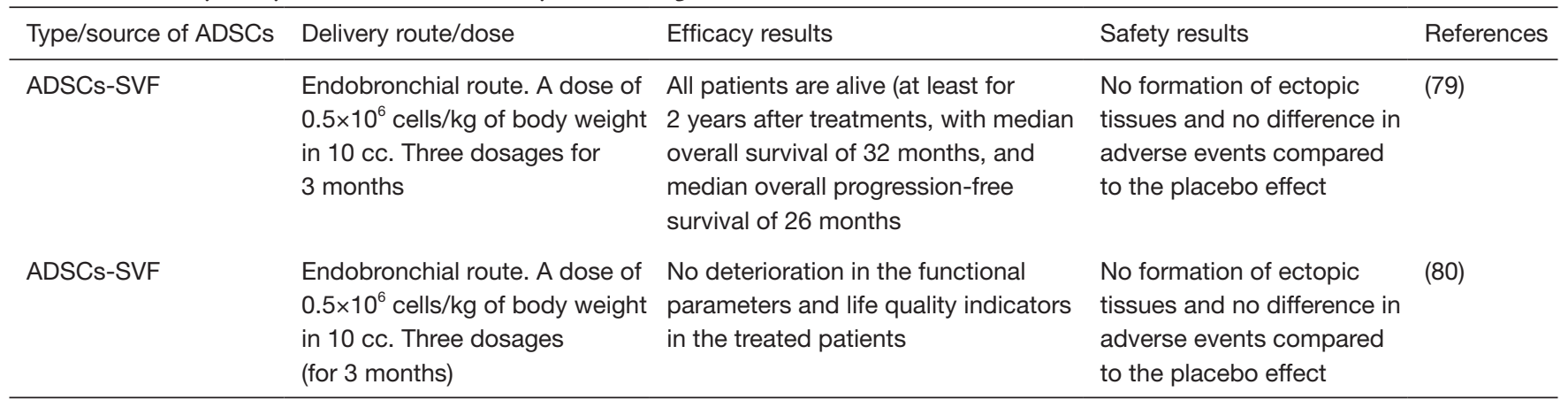

IPF, Idiopathic pulmonary fibrosis; ADSCs, adipose-derived MSCs.

culture and in vivo (85). The umbilical cord-derived MSCs (uMSCs) are less readily available compared to ESCs, while the placenta-derived MSCs can engraft in the lung and other solid organs after xenotransplantation. Moodley and colleagues studied the therapeutic effects of uMSCs in BLM-induced lung injury and found that these cells can inhibit lung inflammation and fibrosis by up-regulating anti-inflammatory modulators but downregulating the cytokine expression (61). The systemically administered uMSCs are present in the injured lung after 2 weeks and may not exactly match with the recipient phenotype to avoid the graft-versus host reaction (61).

The effect of transplanted placenta-derived MSCs on lung fibrosis was also studies using murine models. 
Transplantation of allogeneic and xenogeneic placentaderived MSCs notably reduces BLM-induced lung fibrosis by suppression the infiltration of neutrophils, and act as a potential treatment for lung fibrosis (60). Placentaderived MSCs are plastic and have immunomodulation properties and are, therefore, important for lung repair and regeneration like other MSCs (86). A summary of key studies on IPF therapy using placental/umbilical cord MSCs is shown in Tables 3,4.

\section{Adipose tissue-derived mesenchymal stromal/stem cells (ADSCs)}

The adipose tissue contains pluripotent cells that can act as alternative sources of stem cells to BM-MSCs since they can give rise to many cell lineages (87). ADSCs can be isolated easily from patients through liposuction, show good results in cell therapy, and produce many bioactive factors, including the hepatocyte growth factor (HGF) and interleukin (IL-1, IL-6, IL-8) receptor antagonists $(88,89)$. ADSC therapy can improve the detrimental effect of repeating the intra-tracheal instillations of BLM (36). Mechanistically, the ADSC therapy results in a decreased AEC and Clara cell hyperplasia, and a reduction of the thickening of septum, enlargement of alveoli and inflammatory cell infiltrations (36). The elevation of both apoptosis and TGF- $\beta$ levels is also suppressed (36). Furthermore, ADSCs administration can ameliorate the renal function in the acute pyelonephritis animal model (89).

A contradictory effect of ADSCs on lung fibrosis is found when administrating intravenously in rat model of fibrosis since they could not decrease the BLM-induced lung injury (90). In contrast to many other studies, Uji and coworkers infused the isolated ADSCs to rats after long time (14 days) of the BLM instillation that probably leads to the inefficiency of administrated ADSCs in the BLM-induced lung injury (90). Other reasons that are proposed for the treatment failure include the animal age, stage of fibrotic disease and lack of homing capacity of the intravenously administered ADSCs (90). The homing capacity of administrated ADSCS could be improved by modulating these cells with a cocktail of chemokines or growth factors prior to administration (91). The chemotactic response to chemokines and growth factors probably stimulates the migration of the intravenously administrated ADSCs toward injured areas in vivo (91). A summary of key preclinical and clinical studies on IPF therapy using ADSCs is shown in Tables 5,6.

\section{The iPSCs}

A new approach to investigate the applications of iPSCs in IPF treatment is using IPF-specific cells isolated from IPF patients $(37,92)$. Deriving lung tissue-specific stem cells from patients is a key step for establishing human disease models and transplanting lung epithelial cells. The iPSCs are successfully produced from many lung disease patients. However, the use of iPSCs in developing human lung disease models effectively faces many challenges, including the development of effective research techniques that allow converting iPSCs into lung progenitor cells and then into different differentiated lung epithelial cells. However, some studies have shown progress in generating multipotent airway and lung progenitor cells from human patientspecific cystic fibrosis iPSCs. For example, lung progenitor cells are generated by mimicking the developmental environment in which the signaling interactions and events occur in the developing murine lungs (92). The generated human disease-specific lung progenitor cells can form respiratory epithelial cells when engrafting into immunedeficient mice subcutaneously (92). Generating iPSCs from diseased human lungs is, therefore, particularly important, and can create a remarkable platform for the treatment of different lung diseases in humans. A summary of key preclinical and clinical studies on IPF therapy using iPSCs is shown in Table 7 .

\section{Endogenous lung tissue-specific stem cells}

Several studies have identified adult stem cell types in anatomic locations of the lung $(95,96)$. Moreover, resident multipotent lung stem cells were isolated and wellcharacterized from adult mouse lung $(97,98)$. Lung resident stem cells can produce different types of cytokines, growth factors and surfactant proteins, which are specific biomarker of the lung (35,38,39,96,99-101).

Resident MSCs can regulate tissue repair and/or regeneration, and different pathophysiological processes, including inflammation, fibrogenesis, angiogenesis and tumorigenesis in different tissue types. Lung mesenchymal stem cells (L-MSCs) are functionally distinct from other MSCs and are specifically equipped for the pulmonary environment and may play roles in treating chronic lung diseases $(102,103)$. In contrast to the well-investigated effects of exogenously administered MSCs, little is known about the healing effects of endogenous L-MSCs. However, some studies suggest that endogenous stem/progenitor 
Table 7 Summary of key IPF preclinical study results using iPSCs

\begin{tabular}{|c|c|c|c|}
\hline Types/source of iPSCs & Delivery route/dose & Efficacy results & References \\
\hline iPSC conditioned medium & $\begin{array}{l}\text { IV route. A dose of } 2 \times 10^{6} \text { cells } \\
\text { per mouse }\end{array}$ & $\begin{array}{l}\text { Treated mice after BLM instillation show an inhibition } \\
\text { of collagen deposition, neutrophil infiltration and } \\
\text { myeloperoxidase activity, as well as rescued pulmonary } \\
\text { function }\end{array}$ & (94) \\
\hline iPSCs derived to AECII cells & $\begin{array}{l}\text { Intratracheal route. A dose of } \\
5 \times 10^{5} \text { cells per mouse }\end{array}$ & $\begin{array}{l}\text { Treated mice after BLM instillation have decreased collagen } \\
\text { deposition and lung inflammation }\end{array}$ & (35) \\
\hline
\end{tabular}

IPSCs, induced pluripotent stem cells; IPF, Idiopathic pulmonary fibrosis; TGF, transforming growth factor; AECII, alveolar epithelial type II cells; BLM, bleomycin; EMT, epithelial-mesenchymal transition.

cells in the lung, including L-MSCs, contribute to both the maintenance of epithelium and repair/regeneration of injured lungs in vitro and in vivo (103).

L-MSCs have several characteristics such mesenchymal signature, and multi-lineage differentiation capacity to other tissue such as to myo-fibroblasts bone, fat, bone and cartilage $(95,102)$, and Clara, AECI and AECII cells (104), as well as endothelial cells (105) in culture. However, L-MSC differentiation into these different types of cells in vivo is still under question, and the emphasis in L-MSC research has largely shifted to their paracrine effects (106). This probably explains the relatively limited studies that attempted to investigate the use of L-MSCs in the treatment of chronic lung disease $(107,108)$. More research is, therefore, still needed to validate the potential of L-MSC-based therapies for fibrosis and other lung diseases.

\section{Circulating endothelial progenitors (EPCs)}

EPCs have some vascular remodeling and lung tissuespecific repairing properties (109). The association between IPF and the abnormal vascular remodeling is wellestablished (110).

The development of lung vasculature is closely related to the release of some specific factors, including the endothelial-derived angiogenic factors, that promote the alveolization by stimulating the proliferation of lung specific epithelial stem/progenitor cells. Restoring the endothelial cell function and maintenance of lung homeostasis, therefore, make EPCs important cell types in lung development, morphogenesis and repair/regeneration after injury. In addition, defects in lung EPCs can lead to loss of their capacity for repairing the damaged endothelial cells and maintaining the vascular integrity that can lead to several lung diseases. For example, EPC defects may contribute to the lung injury, leading to developing many profibrogenic events and, therefore, EPC transplantation may inhibit lung fibrosis (111). Indeed, in the clinical context of IPF, the EPCs defects can be overcome by increasing the expression levels of the vascular endothelial growth factor (VEGF) (111). Furthermore, EPCs were suggested to contribute directly to angiogenesis, probably by secreting specific angiogenesis-promoting growth factors (112).

\section{Cell delivery routes}

The cell-based therapy for IPF and lung injuries holds great promise. However, the route of administration is still one of the major challenges for this cell-based therapy. In experimental and preclinical studies, cells are administered into the injured lung through different routes, including the intravenous $(57,94)$, intraperitoneal $(36,57)$, and intratracheal $(113,114)$ instillations. Interestingly, the route of cell delivery most likely influences the cell trafficking to the targeted sites in the organ (115) and, therefore, it is an important factor for the success of cell-based therapy of different diseases.

The intra tracheal delivery is normally administered either by an injection of a cell bolus into the lung or by an aerosolizing of droplets with nebulizers $(116,117)$. In addition, the intratracheal delivery of cells is considered as the optimal delivery method since it enables a local cell delivery into the injured sites that can reduce the systemic cell distribution. It may also enhance tissue regeneration by 
increasing the delivered cell number at the injured sites and reducing the pulmonary first-pass effect $(116,117)$.

\section{The effective dose for cell therapy}

Enough cell number reaching the target organ/sties is required for the success of cell-based therapy. The most efficient cell dose for a successful cell therapy is the minimum number of cells that is required to achieve significantly successful and safe outcomes, which varies between different studies. Several attempts have been made to quantitatively evaluate the safety and efficiency of different doses of stem cell types such as MSCs. For example, the IV dose of allogeneic BM-MSCs administered in patients with the first acute myocardial infarction is safe and efficient at the range of $0.5,1.6$ and 5 million cells per kilogram (kg) (118). Notably, among different parameters analyzed for the dose-dependent effect in this study, the premature ventricular contraction exhibited a clear doseresponsiveness (118).

Some preclinical studies used stem cells at doses in a range of $5 \times 10^{5}$ to $5 \times 10^{6}$ cells $/ \mathrm{kg}$ for IPF therapy $(69,119)$. In murine studies, the effective dose for cell-based therapy is normally $1 \times 10^{6}$ cells per $30 \mathrm{~g}$ mouse, which is equivalent to $2.3 \times 10^{9}$ cells per average human. Deciding the effective cell dose for cell-based therapy is critical for both the success and safety of clinical trials in humans.

\section{Timing of the delivery}

The timing of stem cell delivery is a major influencing factor for the success of the cell-based therapy of different human diseases, including IPF (120). For example, in different IPF-inducing strategies and experiments, cells have been transplanted in the IPF model at different time courses; either immediately (66), $15 \mathrm{~min}$ (60), $6 \mathrm{hr}$ (69), $8 \mathrm{hr}$ (81), $24 \mathrm{hr}$ (61), 3 days (121), 4 days (65), or even 1 to 2 months (50) after IPF inductions. However, the early administration of cells within $24 \mathrm{hr}$ of lung injury shows the most promising results in healing fibrotic lesions (53). This is probably due to the immunomodulatory ability of the transplanted cells that can reduce the inflammation and lung epithelial damage, leading to the amelioration of the IPF (53).

Transplanted cells, however, do not show a significant effect on the subsequent collagen deposition and fibrosis prevention, but have some aberrant actions when transplanting few days after the injury (53). In contrast, transplanting AECII cells into the damaged lungs 3, 7, or 15 days after BLM instillation can result in a reduced disposition of collagen in the cell matrix, and lead to a reduction in the IPF severity (31). The findings of this study indicate that AEC II cell therapy can reverse the IPF even after the formation of fibrotic lesions. However, when MSCs are administered at later time points of the fibrosis development, the engrafted cells apparently differentiate into the interstitial tissue cells (the tissue and space around the alveoli), and probably contribute to the fibrosis development (113).

\section{Current IPF clinical trials}

There is currently no effective cure for IPF, but there are some promising preclinical and in vitro data. Stem cellbased therapeutic approaches for human diseases, including IPF, are generally at early experimental phases, and far from mature clinical practices. Several clinical trials on the stem cell-based therapy of IPF are still ongoing $(3,122)$. The major objectives in these clinical trials are the efficacy, safety and tolerability of cell-based therapies in humans. The risk profile in these trials includes the teratoma risk (tumor formation), and risks associated with cell handling methods and the culture/storage protocols, as well as other risks related to the surgical procedures, immunosuppression, comorbidities and allergic immune responses.

Since stem cells are potential candidates for the malignant transformation, the risk of tumor formation for stem cells used in these clinical trials could be high. For example, a patient who received transplanted stem cells has developed a donor-derived multifocal brain tumor 4 years after transplantation, highlighting the potential risk of tumor formation in transplanted stem cells in humans (123).

A major objective of current clinical trials is the efficacy of stem cell therapeutic approaches. Some important questions should be addressed to evaluate the efficacy of a stem cell-based therapeutic approach, including deciding the most appropriate delivery route that enables an efficient recruitment of stem cells to the lung and the appropriate method to induce the functional differentiation of recruited stem cells into lung epithelium to achieve successful therapeutic effects. These questions also include both the ideal dose and time for administration and addressing them properly can lead to an efficient cell-based therapy.

MSCs are the most commonly used stem cells in current clinical trials, because of their low immunogenicity and risk of teratoma, and lack of potential ethical problems $(124,125)$. 
Human placenta- and BM-derived MSCs are, particularly, popular in IPF clinical trials $(126,127)$. However, most IPF clinical trials have not been completed yet, and are still in Phase I and II.

Other treatment methods used in clinical trials have revolutionized the IPF management since 2014 when two new anti-fibrotic agents, Nintedanib and Pirfenidone, have emerged. Both Nintedanib and Pirfenidone have shown an ability for delivering a significate reduction in the progression of chronic IPF and approved for the IPF treatment $(128,129)$. The tyrosine kinase inhibitor Nintedanib can slow the IPF progress by both decreasing the declining rate of the FVC and moderating the impairment of lung functions in IPF patients subjected to clinical trials (129). However, there are still many difficulties that surround the clinical end-point selections in IPF clinical trials (128).

\section{Conclusions, current challenges and future prospects}

Few cell-based therapies have been used in clinics, including BMSC transplantation, which shows a success in replacing the diseased blood system of patients (130), and skin-derived stem cells used for treating patients with severe burns (131). These cell-based therapy also include cord blood stem cells that are used for both cancerous blood disorders such as leukemia (132), and genetic blood diseases like Fanconi anemia in children (133). Interestingly, cell-based therapy can potentially be used to treat various chronic human diseases. Identifying more efficient and safe cell therapy methods is currently underway, but there are also many issues that need to be addressed.

There have been remarkable advances in the lung cellbased therapy and regeneration field most recently when the first stem cell transplantation to regenerate human lung was published by Ma and co-workers $(134,135)$. In a remarkable study, Ma and colleagues have discovered and characterized a new adult stem cell population in humans. Further, they successfully used this novel stem cell population to generate functional air exchange units when transplanting these cells to a murine lung model and in human clinical trials (135).

Furthermore, there are many recent tremendous achievements in the repair, regeneration and engineering of lung tissues with the development of 3D lung culture models, the use of decellularized whole lungs, and the applications of bioengineering approaches to generate functional lung tissue $(38,39,136,137)$. In addition, the use of the decellularized whole lung as a scaffold for recellularization and subsequently lung implantation was intensively investigated $(138,139)$. Indeed, the whole lung model for IPF patients is a promising strategy if the challenges to develop a complex three-dimensional (3D) lung can be overcome. The main challenge for this development is making a successful and well-integrated $3 \mathrm{D}$ network of different lung cell types, including the mesenchymal, epithelial, fibroblast, endothelial, inflammatory, and neuronal cell types, in an appropriate and well-established environment where they can effectively function.

The susceptibility to the development of IPF is associated with the genetic polymorphism of certain genes (140-142). Hence, combining cell-based therapy and gene therapy may offer a new strategy for IPF intervention. This has been proposed by developing genetically modified stem cells using viral vectors targeting IPF disease (81). Lung fibrosis such as cystic fibrosis, is indeed an ideal gene therapy target, compared to other lung diseases for several reasons, including the ease of access to the lung, and both CFTR gene cloning and characterization (143). However, this kind of therapy still have several barriers and challenges (143).

Genetically modified stem cells can be delivered specifically to the injured lung sites and, therefore, can deliver certain genes to be expressed in these lung sites. Progress toward identifying the appropriate specific stem cell population for gene therapy in the airway, and the appropriate gene vector that provides a sustained expression is still an ongoing challenge. One major challenge is the generation of vector-specific tolerance in human patients through the modification of the response of the host immune system to the gene therapy vector that will facilitate the administration of the gene therapy vector. Other major factors for the success of the gene therapy are their safety and effectiveness that are currently under intensive investigation.

Another future direction is utilizing the cytokine effects on targeted cells to improve the cell-based therapy. This will be largely based on our understanding of the functional roles of cytokines and signaling molecules in enhancing the efficacy of both immune cells and cells responsible for healing the damaged lung, which are well investigated (144). The efficient cell-based therapy approach is, therefore, largely dependent on identifying the appropriate cytokines 
for cell treatments.

\section{Acknowledgments}

None.

\section{Footnote}

Conflicts of Interest: The authors have no conflicts of interest to declare.

Ethical Statement: The authors are accountable for all aspects of the work in ensuring that questions related to the accuracy or integrity of any part of the work are appropriately investigated and resolved.

\section{References}

1. Weiss D. Cell therapy approaches for lung diseases. Hum Gene Ther 2011;22:A6.

2. Barratt SL, Creamer A, Hayton C, et al. Idiopathic Pulmonary Fibrosis (IPF): An Overview. J Clin Med 2018;7:201.

3. Lederer DJ, Martinez FJ. Idiopathic Pulmonary Fibrosis. N Engl J Med 2018;378:1811-23.

4. Myllärniemi M, Kaarteenaho R. Pharmacological treatment of idiopathic pulmonary fibrosis-preclinical and clinical studies of pirfenidone, nintedanib, and Nacetylcysteine. European Clin Resp J 2015;2.

5. Richeldi L, Collard HR, Jones MG. Idiopathic pulmonary fibrosis. Lancet 2017;389:1941-52.

6. Maher TM, Wells AU, Laurent GJ. Idiopathic pulmonary fibrosis: multiple causes and multiple mechanisms? Eur Respir J 2007;30:835-9.

7. Israël-Biet $\mathrm{D}$, Juvin $\mathrm{K}$, Tran KD, et al. Idiopathic pulmonary fibrosis: diagnosis and treatment in 2013. Rev Pneumol Clin 2014;70:108-17

8. Caminati A, Madotto F, Cesana G, et al. Epidemiological studies in idiopathic pulmonary fibrosis: pitfalls in methodologies and data interpretation. Eur Respir Rev 2015;24:436-44.

9. Nogee LM, Dunbar AE, Wert SE, et al. A mutation in the surfactant protein $\mathrm{C}$ gene associated with familial interstitial lung disease. New Engl J Med 2001;344:573-9.

10. Bullard JE, Nogee LM. Heterozygosity for ABCA3 mutations modifies the severity of lung disease associated with a surfactant protein C gene (SFTPC) mutation. Pediatr Res 2007;62:176-9.
11. Armanios M, Blackburn EH. The telomere syndromes. Nat Rev Genet 2012;13:693-704.

12. Liu T, Ullenbruch $M$, Young Choi $Y$, et al. Telomerase and telomere length in pulmonary fibrosis. Am J Respir Cell Mol Biol 2013;49:260-8.

13. Fernández Pérez ER, Daniels CE, Schroeder DR, et al. Incidence, prevalence, and clinical course of idiopathic pulmonary fibrosis: a population-based study. Chest 2010;137:129-37.

14. Raghu G, Chen SY, Yeh WS, et al. Idiopathic pulmonary fibrosis in US Medicare beneficiaries aged 65 years and older: incidence, prevalence, and survival, 2001-11. Lancet Respir Med 2014;2:566-72.

15. Margaritopoulos GA, Giannarakis I, Siafakas NM, et al. An update on idiopathic pulmonary fibrosis. Panminerva Med 2013;55:109-20.

16. Raghu G, Selman M. Nintedanib and pirfenidone. New antifibrotic treatments indicated for idiopathic pulmonary fibrosis offer hopes and raises questions. Am J Respir Crit Care Med 2015;191:252-4.

17. Uzunhan $Y$, Nunes $H$, Gille T, et al. Innovative therapeutics for idiopathic pulmonaryfibrosis. Presse Med 2011;40:1100-12.

18. Ahluwalia N, Shea B, Tager A. New therapeutic targets in idiopathic pulmonary fibrosis aiming to rein in runaway wound-healing responses. Am J Respir Crit Care Med 2014;190:867-78.

19. Marshall RP, Gohlke P, Chambers RC, et al. Angiotensin II and the fibroproliferative response to acute lung injury. Am J Physiol Lung Cell Mol Physiol 2004;286:L156-64.

20. Laleu B, Gaggini F, Orchard M, et al. First in class, potent, and orally bioavailable NADPH oxidase isoform 4 (Nox4) inhibitors for the treatment of idiopathic pulmonary fibrosis. J Med Chem 2010;53:7715-30.

21. Mackinnon AC, Gibbons MA, Farnworth SL, et al. Regulation of transforming growth factor-beta 1-driven lung fibrosis by galectin-3. Am J Respir Crit Care Med 2012;185:537-46.

22. Al-Tamari HM, Dabral S, Schmall A, et al. FoxO3 an important player in fibrogenesis and therapeutic target for idiopathic pulmonary fibrosis. EMBO Mol Med 2018;10:276-93.

23. Bacha N C, Blandinieres A, Rossi E, et al. Endothelial Microparticles are Associated to Pathogenesis of Idiopathic Pulmonary Fibrosis. Stem Cell Rev Rep 2017;2:1-13.

24. Raghu G. Pharmacotherapy for idiopathic pulmonary fibrosis: current landscape and future potential. Eur Respir Rev 2017;26:170071. 
25. Tepede A, Yogaratnam D. Nintedanib for Idiopathic Pulmonary Fibrosis. J Phar Prac 2017;(3):897190017735242.

26. Matthay MA, Anversa P, Bhattacharya J, et al. Cell therapy for lung diseases report from an NIH-NHLBI Workshop, November 13-14, 2012. Am J Respir Crit Care Med 2013;188:370-5.

27. Ghadiri M, Young PM, Traini D. Cell-based therapies for the treatment of idiopathic pulmonary fibrosis (IPF) disease. Expert Opin Biol Ther 2016;16:375-87.

28. Geiger S, Hirsch D, Hermann FG. Cell therapy for lung disease. Eur Respir Rev 2017;26:1-7.

29. Tzouvelekis A, Toonkel R, Karampitsakos T, et al. Mesenchymal Stem Cells for the Treatment of Idiopathic Pulmonary Fibrosis. Front Med (Lausanne) 2018;5:142.

30. Serrano-Mollar A. Cell Therapy in Idiopathic Pulmonary Fibrosis. Med Sci (Basel) 2018;6:64.

31. Serrano-Mollar A, Nacher M, Gay-Jordi G, et al. Intratracheal transplantation of alveolar type ii cells reverses bleomycin-induced lung fibrosis. Am J Respir Crit Care Med 2007;176:1261-8.

32. Tanaka K, Fujita T, Umezawa H, et al. Therapeutic effect of lung mixed culture-derived epithelial cells on lung fibrosis. Lab Invest 2014;94:1247-59.

33. Banerjee ER, Laflamme MA, Papayannopoulou T, et al. Human embryonic stem cells differentiated to lung lineage-specific cells ameliorate pulmonary fibrosis in a xenograft transplant mouse model. PLoS One 2012;7:e33165.

34. Toonkel RL, Hare JM, Matthay MA, et al. Mesenchymal stem cells and idiopathic pulmonary fibrosis potential for clinical testing. Am J Respir Crit Care Med 2013;188:133-40.

35. Zhou Q, Ye XL, Sun RW, et al. Differentiation of mouse induced pluripotent stem cells into alveolar epithelial cells in vitro for use in vivo. Stem Cells Transl Med 2014;3:675-85.

36. Lee SH, Lee EJ, Lee SY, et al. The effect of adipose stem cell therapy on pulmonary fibrosis induced by repetitive intratracheal bleomycin in mice. Exp Lung Res 2014;40:117-25.

37. Barczyk M, Schmidt M, Mattoli S. Stem cell-based therapy in idiopathic pulmonary fibrosis. Stem Cell Rev 2015;11:598-620.

38. El-Hashash AH. Lung stem cell behavior. Berlin: Springer, 2018:105.

39. El-Hashash AH, Abdel Magid E. The lung: developmental morphogenesis, mechanobiology and stem cells. Singapore: World Scientific Publish, 2019:180.

40. Barkauskas CE, Cronce MJ, Rackley CR, et al. Type 2 alveolar cells are stem cells in adult lung. J Clin Invest 2013;123:3025-36.

41. Jeong JO, Han JW, Kim JM, et al. Malignant tumor formation after transplantation of short-term cultured bone marrow mesenchymal stem cells in experimental myocardial infarction and diabetic neuropathy. Circ Res 2011;108:1340-7.

42. Ma N, Gai H, Mei J, et al. Bone marrow mesenchymal stem cells can differentiate into type II alveolar epithelial cells in vitro. Cell Biol Int 2011;35:1261-6.

43. Rippon HJ, Ali NN, Polak JM, et al. Initial observations on the effect of medium composition on the differentiation of murine embryonic stem cells to alveolar type II cells. Cloning Stem Cells 2004;6:49-56.

44. Coraux C, Nawrocki-Raby B, Hinnrasky J, et al. Embryonic stem cells generate airway epithelial tissue. Am J Respir Cell Mol Biol 2005;32:87-92.

45. Cores J, Hensley MT, Kinlaw K, et al. Safety and Efficacy of Allogeneic Lung Spheroid Cells in a Mismatched Rat Model of Pulmonary Fibrosis. Stem Cells Transl Med 2017;6:1905-16.

46. Guillamat-Prats R, Gay-Jordi G, Xaubet A, et al. Alveolar type II cell transplantation restores pulmonary surfactant protein levels in lung fibrosis. J Heart Lung Transplant 2014;33:758-65.

47. Garcia O, Carraro G, Turcatel G, et al. Amniotic fluid stem cells inhibit the progression of bleomycininduced pulmonary fibrosis via CCL2 modulation in bronchoalveolar lavage. PLoS One 2013;8:e71679.

48. Serrano-Mollar A, Gay-Jordi G, Guillamat-Prats R, et al. Safety and tolerability of alveolar type II cell transplantation in idiopathic pulmonary fibrosis. Chest 2016;150:533-43.

49. Rafii R, Juarez M, Albertson T, et al. A review of current and novel therapies for idiopathic pulmonary fibrosis. J Thorac Dis 2013;5:48-73.

50. Schlötzer-Schrehardt U, Freudenberg U, Kruse FE. The emerging technology of tissue engineering: Focus on stem cell niche. Ophthalmologe 2017;114:327-40.

51. Fitzsimmons RE, Mazurek MS, Soos A, et al. Mesenchymal Stromal/Stem Cells in Regenerative Medicine and Tissue Engineering. Stem Cells Int 2018;2018:8031718.

52. Keating A. Mesenchymal stromal cells: new directions. Cell Stem Cell 2012;10:709-16.

53. Yan X, Liu Y, Han Q, et al. Injured microenvironment 
directly guides the differentiation of engrafted Flk$1(+)$ mesenchymal stem cell in lung. Exp Hematol 2007;35:1466-75.

54. Kurtz A. Mesenchymal stem cell delivery routes and fate. Int J Stem Cells 2008;1:1-7.

55. Ghionzoli M, Cananzi M, Zani A, et al. Amniotic fluid stem cell migration after intraperitoneal injection in pup rats: implication for therapy. Pediatr Surg Int 2010;26:79-84.

56. Kusuma GD, Carthew J, Lim R, et al. Effect of the microenvironment on mesenchymal stem cells paracrine signalling: opportunities to engineer the therapeutic effect. Stem Cells Dev 2017;26:617-31.

57. Yousefi F, Ebtekar M, Soleimani M, et al. Comparison of in vivo immunomodulatory effects of intravenous and intraperitoneal administration of adipose-tissue mesenchymal stem cells in experimental autoimmune encephalomyelitis (EAE). Int Immunopharmacol 2013;17:608-16.

58. Conese M, Carbone A, Castellani S, et al. Paracrine effects and heterogeneity of marrow-derived stem/progenitor cells: relevance for the treatment of respiratory diseases. Cells Tissues Organs 2013;197:445-73.

59. Li F, Han F, Li H, et al. Human placental mesenchymal stem cells of fetal origins alleviated inflammation and fibrosis by attenuating MyD88 signaling in bleomycininduced pulmonary fibrosis mice. Mol Immunol 2017;90:11-21.

60. Cargnoni A, Gibelli L, Tosini A, et al. Transplantation of allogeneic and xenogeneic placenta-derived cells reduces bleomycin-induced lung fibrosis. Cell Transplant 2009; 18:405-22.

61. Moodley Y, Atienza D, Manuelpillai U, et al. Human umbilical cord mesenchymal stem cells reduce fibrosis of bleomycin-induced lung injury. Am J Pathol 2009; 175:303-13.

62. Jun D, Garat C, West J, et al. The pathology of bleomycininduced fibrosis is associated with loss of resident lung mesenchymal stem cells that regulate effector T.-cell proliferation. Stem Cells 2011;29:725-35.

63. Moodley Y, Vaghjiani V, Chan J, et al. Anti-inflammatory effects of adult stem cells in sustained lung injury: A comparative study. PLoS One 2013;8:e69299.

64. Huleihel L, Sellares J, Cardenes N, et al. Modified mesenchymal stem cells using miRNA transduction alter lung injury in a bleomycin model. Am J Physiol Lung Cell Mol Physiol 2017;313:L92-103.

65. Gazdhar A, Susuri N, Hostettler K, et al. HGF expressing stem cells in usual interstitial pneumonia originate from the bone marrow and are antifibrotic. Plos One 2013;8:e65453.

66. Ortiz LA, Gambelli F, McBride C, et al. Mesenchymal stem cell engraftment in lung is enhanced in response to bleomycin exposure and ameliorates its fibrotic effects. Proc Natl Acad Sci U S A 2003;100:8407-11.

67. Ortiz LA, Dutreil M, Fattman C, et al. Interleukin 1 receptor antagonist mediates the antiinflammatory and antifibrotic effect of mesenchymal stem cells during lung injury. Proc Natl Acad Sci USA 2007;104:11002-7.

68. Huang K, Kang X, Wang X, et al. Conversion of bone marrow mesenchymal stem cells into type II alveolar epithelial cells reduces pulmonary fibrosis by decreasing oxidative stress in rats. Mol Med Rep 2015;11:1685-92.

69. Rojas M, Xu JG, Woods CR, et al. Bone marrow-derived mesenchymal stem cells in repair of the injured lung. Am J Respir Cell Mol Biol 2005;33:145-52.

70. Lee SH, Jang AS, Kim YE, et al. Modulation of cytokine and nitricoxide by mesenchymal stem cell transfer in lung injury/fibrosis. Respir Res 2010;11:16.

71. Ono M, Ohkouchi S, Kanehira M, et al. Mesen chymalstemcellscorrectinappropriateepithelialmesenchymerelationinpulmonary fibrosis using stanniocalcin-1. Mol Ther 2015;23:549-60.

72. Liebler JM, Lutzko C, Banfalvi A, et al. Retention of human bone marrow-derived cells in murine lungs following bleomycin-induced lung injury. Am J Physiol Lung Cell Mol Physiol 2008;295:L285-92.

73. Lan YW, Choo KB, Chen CM, et al. Hypoxiapreconditioned mesenchymal stem cells attenuate bleomycin-induced pulmonary fibrosis. Stem Cell Res Ther 2015;6,97.

74. Cahill EF, Kennelly H, Carty F, et al. Hepatocyte growth factor is required for mesenchymal stromal cell protection against bleomycin-induced pulmonary fibrosis. Stem Cells Transl Med 2016;5:1307-18.

75. Chambers DC, Enever D, Ilic N, et al. A phase $1 \mathrm{~b}$ study of placenta-derived mesenchymal stromal cells in patients with idiopathic pulmonary fibrosis. Respirology 2014;19:1013-8.

76. Glassberg MK, Minkiewicz J, Toonkel RL, et al. Allogeneic human mesenchymal stem cells in patients with idiopathic pulmonary fibrosis via intravenous delivery (AETHER): a phase I safety clinical trial. Chest 2017;151:971-81.

77. Kotani T, Masutani R, Suzuka T, et al. Anti-inflammatory and anti-fibrotic effects of intravenous adipose-derived stem cell transplantation in a mouse model of bleomycininduced interstitial pneumonia. Sci Rep 2017;7:14608. 
78. Tashiro J, Elliot SJ, Gerth DJ, et al. Therapeutic benefits of young, but not old, adipose-derived mesenchymal stem cells in a chronic mouse model of bleomycin-induced pulmonary fibrosis. Transl Res 2015;166:554-67.

79. Ntolios P, Manoloudi E, Tzouvelekis A, et al. Longitudinal outcomes of patients enrolled in a phase Ib clinical trial of the adipose-derived stromal cells-stromal vascular fraction in idiopathic pulmonary fibrosis. Clin Respir J 2018;12:2084-9.

80. Tzouvelekis A, Paspaliaris V, Koliakos G, et al. A prospective, non-randomized, no placebo-controlled, phase Ib clinical trial to study the safety of the adipose derived stromal cells-stromal vascular fraction in idiopathic pulmonary fibrosis. J Transl Med 2013;11:171.

81. Aguilar S, Scotton CJ, McNulty K, et al. Bone marrow stem cells expressing keratinocyte growth factor via an indu- cible lentivirus protects against bleomycin-induced pul- monary fibrosis. PloS One 2009;4:e8013.

82. Yamada M, Kubo H, Kobayashi S, et al. Bone marrowderived progenitor cells are important for lung repair after lipopolysaccharide-induced lung injury (vol 172, pg 1266, 2004). J Immunol 2004;173:4755.

83. Cosenza S, Ruiz M, Toupet K, et al. Mesenchymal stem cells derived exosomes and microparticles protect cartilage and bone from degradation in osteoarthritis. Sci Rep 2017;7:16214.

84. Cárdenes N, Álvarez D, Sellarés J, et al. Senescence of bone marrow-derived mesenchymal stem cells from patients with idiopathic pulmonary fibrosis. Stem Cell Res Ther 2018;9:257.

85. Can A, Balci D. Isolation, culture, and characterization of human umbilical cord stroma-derived mesenchymal stem cells. Methods Mol Biol 2011;698:51-62.

86. Antoniou KM, Karagiannis K, Tsitoura E, et al. Clinical applications of mesenchymal stem cells in chronic lung diseases. Biomed Rep 2018;8:314-8.

87. Kolonin MG, Evans KW, Mani SA, et al. Alternative origins of stroma in normal organs and disease. Stem Cell Res 2012;8:312-23.

88. Gimble JM, Katz AJ, Bunnell BA. Adipose-derived stem cells for regenerative medicine. Circ Res 2007;100:1249-60.

89. Sabetkish S, Sabetkish N, Talebi MA, et al. The role of nonautologous and autologous adipose-derived mesenchymal stem cell in acute pyelonephritis. Cell Tissue Bank 2018;19:301-9.

90. Uji M, Nakada A, Nakamura T. Intravenous administration of adipose-derived stromal cells does not ameliorate bleomycin-induced lung injury in rats. Open J Regenerative Med 2013;2:39-45.

91. Baek SJ, Kang SK, Ra JC. In vitro migration capacity of human adipose tissue-derived mesenchymal stem cells reflects their expression of receptors for chemokines and growth factors. Exp Mol Med 2011;43:596-603.

92. Mou H, Zhao R, Sherwood R, et al. Generation of multipotent lung and airway progenitors from mouse escs and patient-specific cystic fibrosis iPSCs. Cell Stem Cell 2012;10:385-97.

93. Zhou Y, He Z, Gao Y, et al. Induced pluripotent stem cells inhibit bleomycin-induced pulmonary fibrosis in mice through suppressing TGF- $\beta 1 /$ Smad-mediated epithelial to mesenchymal transition. Front Pharmacol 2016;7:430.

94. How CK, Chien Y, Yang KY, et al. Induced pluripotent stem cells mediate the release of interferon gammainduced protein 10 and alleviate bleomycin-induced lung inflammation and fibrosis. Shock 2013;39:261-70.

95. Martin J, Helm K, Ruegg P, et al. Adult lung side population cells have mesenchymal stem cell potential. Cytotherapy 2008;10:140-51.

96. Bertoncello I, McQualter JL. Lung stem cells: do they exist? Respirology 2013;18:587-95.

97. Hegab AE, Kubo H, Fujino N, et al. Isolation and characterization of murine multipotent lung stem cells. Stem Cells Dev 2010;19:523-536.

98. Gadepalli VS, Vaughan C, Rao RR. Isolation and characterization of murine multipotent lung stem cells. Methods Mol Biol 2013;962:183-91.

99. Spees JL, Pociask DA, Sullivan DE, et al. Engraftment of bone marrow progenitor cells in a rat model of asbestosinduced pulmonary fibrosis. Am J Respir Crit Care Med 2007;176:385-94.

100.Ibrahim A, El-Hashash A. Lung stem cell behavior in development and regeneration. Edorium J Stem Cell Research and Therapy 2015;1:1-13.

101.Zhu Y, Chen X, Yang X, et al. Stem cells in lung repair and regeneration: current applications and future promise. J Cell Physiol 2018;233:6414-24.

102.Foronjy RF, Majka SM. The potential for resident lung mesenchymal stem cells to promote functional tissue regeneration: understanding microenvironmental cues. Cells 2012;1:874.

103. Collins JJ, Thebaud B. Lung mesenchymal stromal cells in development and disease: to serve and protect? Antioxid Redox Signal 2014;21:1849-62.

104. Gong X, Sun ZR, Cui D, et al. Isolation and characterization of lung resident mesenchymal stem cells 
capable of differentiating into alveolar epithelial type II cells. Cell Biol Int 2014;38:405-11.

105. Yamamoto Y, Baldwin HS, Prince LS. Endothelial differentiation by multipotent fetal mouse lung mesenchymal cells. Stem Cells Dev 2012;21:1455-65.

106. Chapman HA, Li XP, Alexander JP, et al. Integrin alpha 6 beta 4 identifies an adult distal lung epithelial population with regenerative potential in mice. J Clin Invest 2011;121:2855-62.

107.Hegab AE, Ha VL, Gilbert JL, et al. Novel stem/ progenitor cell population from murine tracheal submucosal gland ducts with multipotent regenerative potential. Stem Cells 2011;29:1283-93.

108. Kumar PA, Hu Y, Yamamoto Y, et al. Distal airway stem cells yield alveoli in vitro and during lung regeneration following h1n1 influenza infection. Cell 2011;147:525-38.

109.Smadja DM, Dorfmuller P, Guerin CL, et al. Cooperation between human fibrocytes and endothelial colony-forming cells increases angiogenesis via the CXCR4 pathway. Thromb Haemost 2014;112:1002-13.

110. Barratt S, Millar A. Vascular remodelling in the pathogenesis of idiopathic pulmonary fibrosis. QJM 2014;107:515-9.

111. Malli F, Koutsokera A, Paraskeva E, et al. Endothelial progenitor cells in the pathogenesis of idiopathic pulmonary fibrosis: an evolving concept. PloS One 2013;8:e53658.

112.Smadja DM, Mauge L, Nunes H, et al. Imbalance of circulating endothelial cells and progenitors in idiopathic pulmonary fibrosis. Angiogenesis 2013;16:147-57.

113. Yunt ZX, Mohning MP, Barthel L, et al. Kinetics of the angiogenic response in lung endothelium following acute inflammatory injury with bleomycin. Exp Lung Res 2014;40:415-25.

114. Silva JD, Paredes BD, Araujo IM, et al. Effects of bone marrow-derived mononuclear cells from healthy or acute respiratory distress syndrome donors on recipient lunginjured mice. Crit Care Med 2014;42:e510-24.

115. Kean TJ, Lin P, Caplan AI, et al. MSCs: delivery routes and engraftment, cell-targeting strategies, and immune modulation. Stem Cells Int 2013;2013:732742.

116. Petersen TH, Calle EA, Niklason LE. Strategies for lung regeneration. Materials Today 2011;14:196-201.

117.Sosnowski TR, Kurowska A, Butruk B, et al. Spraying of cell colloids in medical atomizers. Chem Eng Trans 2013;32:2257-62.

118. Hare JM, Traverse JH, Henry TD, et al. A randomized, double-blind, placebo-controlled, dose-escalation study of intravenous adult human mesenchymal stem cells (prochymal) after acute myocardial infarction. J Am Coll Cardiol 2009;54:2277-86.

119. Martinez FJ, Collard HR, Pardo A, et al. Idiopathic pulmonary fibrosis. Nat Rev Dis Primers 2017;3:17074.

120.Huleihel L, Levine M, Rojas M. The potential of cellbased therapy in lung diseases. Expert Opin Biol Ther 2013;13:1429-40.

121. Kumamoto M, Nishiwaki T, Matsuo N, et al. Minimally cultured bone marrow mesenchymal stem cells ameliorate fibrotic lung injury. Eur Respir J 2009;34:740-8.

122. Harari S, Caminati A. Idiopathic pulmonary fibrosis: from clinical trials to real-life experiences. Eur Respir Rev 2015;24:420-7.

123. Amariglio N, Hirshberg A, Scheithauer BW, et al. Donorderived brain tumor following neural stem cell transplantation in an ataxia telangiectasia patient. PLoS Med 2009;6:e1000029.

124. Herberts CA, Kwa MS, Hermsen HP. Risk factors in the development of stem cell therapy. J Transl Med 2011;9:29.

125.Suzuki T, Mayhew C, Sallese A, et al. Use of induced pluripotent stem cells to recapitulate pulmonary alveolar proteinosis pathogenesis. Am J Respir Crit Care Med 2014;189:183-93.

126. Ilić N, Atkinson K. Manufacturing and use of human placenta-derived mesenchymal stromal cells for phase I clinical trials: establishment and evaluation of a protocol. Vojnosanit Pregl 2014;71:651-9.

127. Tan JL, Chan ST, Wallace EM, et al. Human amnion epithelial cells mediate lung repair by directly modulating macrophage recruitment and polarization. Cell Trans 2014;23:319-28.

128. George PM, Wells AU. Pirfenidone for the treatment of idiopathic pulmonary fibrosis. Expert Rev Clin Pharmacol 2017;10:483-91.

129. Hajari Case A, Johnson P. Clinical use of nintedanib in patients with idiopathic pulmonary fibrosis. BMJ Open Respir Res 2017;4:e000192.

130. Lazarus HM. Acute leukemia in adults: novel allogeneic transplant strategies. Hematology 2012;17 Suppl 1:S47-51.

131.Fang T, Lineaweaver WC, Sailes FC, et al. Clinical application of cultured epithelial autografts on acellular dermal matrices in the treatment of extended burn injuries. Ann Plast Surg 2014;73:509-15.

132. Grupp SA, Kalos M, Barrett D, et al. Chimeric antigen receptor-modified $\mathrm{T}$ cells for acute lymphoid leukemia. $\mathrm{N}$ Engl J Med 2013;368:1509-18.

133.Smith AR, Wagner JE. Alternative haematopoietic stem 
cell sources for transplantation: place of umbilical cord blood. Br J Haematol 2009;147:246-61.

134. Wang S, Wu J, Liu GH. First stem cell transplantation to regenerate human lung. Protein Cell 2018;9:244-5.

135.Ma Q, Ma Y, Dai X, et al. Regeneration of functional alveoli by adult human SOX9+ airway basal cell transplantation. Protein Cell 2018;9:267-82.

136. Harrington H, Cato P, Salazar F, et al. Immunocompetent 3D model of human upper airway for disease modeling and in vitro drug evaluation. Mol Pharm 2014;11:2082-91.

137. Gilpin SE, Wagner DE. Acellular human lung scaffolds to model lung disease and tissue regeneration. Eur Respir Rev 2018;27:180021.

138. Wagner DE, Bonvillain RW, Jensen T, et al. Can stem cells be used to generate new lungs? Ex vivo lung bioengineering with decellularized whole lung scaffolds. Respirology 2013;18:895-911.

139. Mendez JJ, Ghaedi M, Steinbacher D, et al. Epithelial cell differentiation of human mesenchymal stromal cells in decellularized lung scaffolds. Tissue Eng Part A

doi: $10.21037 /$ sci.2019.06.09

Cite this article as: Lu Q, El-Hashash AH. Cell-based therapy for idiopathic pulmonary fibrosis. Stem Cell Investig 2019;6:22.
2014;20:1735-46.

140. Tzouvelekis A, Kaminski N. Epigenetics in idiopathic pulmonary fibrosis. Biochem Cell Biol 2015;93:159-70.

141.Xu L, Bian W, Gu XH, et al. Genetic polymorphism in matrix metalloproteinase- 9 and transforming growth factor-b1 and susceptibility to combined pulmonary fibrosis and emphysema in a Chinese population. Kaohsiung J Med Sci 2017;33:124e129.

142. Yang IV, Schwartz DA. Epigenetics of idiopathic pulmonary fibrosis. Transl Res 2015;165:48-60.

143. Kotzamanis G, Kotsinas A, Papalois A, et al. Gene therapy - tools and potential applications. 22. targeting the lung: challenges in gene therapy for cystic fibrosis. InTech 2013. Available online: http://www.intechopen.com/books/genetherapy-tools-and-potential-applications/targeting-thelung-challenges-in-gene-therapy-for-cystic-fibrosis

144.Zimmermann JA, McDevitt TC. Pre-conditioning mesenchymal stromal cell spheroids for immunomodulatory paracrine factor secretion. Cytotherapy 2014;16:331-45. 